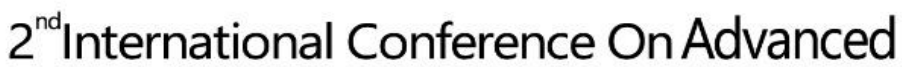 Research in HUMANITIES
}

MILAN, ITALY

\section{Consumers Preference for Distilled Liquor in Abeokuta Impact of Branding On}

\author{
Ogundipe, Kayode Samuel \\ Moshood Abiola Polytechnic Ojere Abeokuta and Sollem Larry Nigeria Limited
}

\begin{abstract}
:
The research investigated the impact of branding on preference for distilled liquor products in Abeokuta metropolis. The aim is to determine how brand name and image affect consumers' choice of a brand of distilled liquor. The research is a descriptive survey. It obtained a sample of 200 consumers of distilled liquor across twenty (20) alcoholic consuming spots in Abeokuta. A multistage sampling was adopted in the selection of respondents and Ordinary Least Square Regression as the analytical technique. It is found that demographic factors such as age, educational qualifications and occupation are statistically significant to determine consumption of alcoholic liquor ( $\mathrm{p}$-value < 0.05). It is also found that brand name and image significantly enhance consumer preference for distilled liquors in Abeokuta (p-value < 0.05). Brand name is however considered to be a paramount reason for consumption of these liquors. The study then recommends that since consumer cannot measure the differences among variety of liquors in term of value, distilling firms should build its strength around the name of the product to suit consumer orientation.
\end{abstract}

Keywords: Brand name, Brand image, Consumer preference, Distilled products 